\title{
ELECTROCHEMISTRY AND SPECTROELECTROCHEMISTRY OF POLYNUCLEAR ZINC PHTHALOCYANINES: FORMATION OF MIXED VALENCE CATION RADICAL SPECIES
}

\author{
V. MANIVANNAN $\dagger$, W. ANDREW NEVIN $\ddagger$ CLIFFORD C. LEZNOFF, \\ and A. B. P. LEVER* \\ Department of Chemistry, York University, North York, Ontario, Canada, M3J 1P3.
}

\begin{abstract}
The electrochemistry and spectroelectrochemistry of mononuclear, binuclear and tetranuclear zinc neopentoxy-substituted phthalocyanines are presented. The binuclear and tetranuclear species show two oxidation waves to the radical cation indicating the existence of stable mixed-valence, half-oxidized species. The electronic spectra of the half- and fully-oxidized species are presented and discussed. Nernstian analysis shows that pairs of phthalocyanine rings are oxidized simultaneously in the tetranuclear species, via a one-electron oxidation pathway.
\end{abstract}

Keywords: phthalocyanine, electrochemistry, spectroelectrochemistry, zinc, complexes

\section{INTRODUCTION}

Certain binuclear porphyrins and phthalocyanines (Pc) containing two metal centres have recently been found to produce species with mixed-metal valencies. For example, electrochemical studies of binary cofacial dicobalt porphyrin complexes show that the cobalt centres are oxidized or reduced separately in two different monoelectronic steps to give mixed-valence compounds containing $\left[\mathrm{Co}^{\mathrm{III}} \mathrm{Co}^{\mathrm{II}}\right]$ and $\left[\mathrm{Co}^{1} \mathrm{Co}^{11}\right]$ metal centres respectively. ${ }^{1}$ Binuclear cobalt phthalocyanines either linked by a common benzene ring ${ }^{2}$ or a 1,8-naphthalene bridge, ${ }^{3}$ form mixed-valence metal centres $\left[\mathrm{Co}^{\prime \prime} \mathrm{Co}^{\prime}\right]$ upon electrochemical reduction. Collman et al., have reported stable mixed-valence ruthenium $\left[\mathrm{Ru}^{\mathrm{III}} \mathrm{Ru}^{\mathrm{II}}\right]$ and $\left[\mathrm{Os}^{\mathrm{III}} \mathrm{Os}{ }^{\mathrm{II}}\right]$ porphyrins. ${ }^{4,5}$

Bis(phthalocyaninato)lanthanide(III) derivatives of the structure [Pc( -1$) \operatorname{Ln}($ III)$\operatorname{Pc}(-2)],{ }^{6,7}$ in which a trivalent lanthanide cation is sandwiched between a phthalocyanine and a one-electron oxidized phthalocyanine, have been prepared. $^{8-14}$ These complexes undergo reversible one-electron chemical and electrochemical oxidations to the doubly oxidized $\pi$-cation species $\left.[\mathrm{Pc}(-1))_{2} \operatorname{Ln}(\mathrm{III})\right]^{+}$, or reduction to $\left[(\mathrm{Pc}(-2))_{2} \operatorname{Ln}(\mathrm{III})\right]^{-}$. Similarly, binuclear mixed-valence porphyrin

* Author for correspondence

tCurrent address (VM): Dept. of Chemistry, University of Western Ontario, London, Ont.. Canada N6A $5 \mathrm{~B} 7$

† Current address (WAN): Central Research Laboratories, Kanegatuchi Chemical Industry Co. Ltd., 2 80, 1-Chome, Yoshida-cho, Hyogo-ku, KOBE 652, Japan. 
species, in which one of the rings is oxidized to its $\pi$-cation radical have also been reported for some trivalent lanthanide sandwich-like bis-porphyrins; while a cerium(IV) bis(porphyrin) has been found to form a mixed-valence ring-oxidized species by chemical or electrochemical oxidation. ${ }^{15} \mathrm{~A}$ planar laterally bridged binuclear (metal-free or zinc) porphyrin has been observed to undergo four consecutive oneelectron reductions, although no mixed valence species were reported. ${ }^{16} \mathrm{~A}$ $[(\mathrm{OEP}) \mathrm{Nb}]_{2} \mathrm{O}_{3}$ binuclear complex has been reported to undergo stepwise oneelectron oxidation to a mixed-valence ring-oxidized species by electrochemical oxidation. ${ }^{17}$ Oligomeric silicon phthalocyanines show stepwise oxidation or reduction of the phthalocyanine rings. ${ }^{18,19}$ Our interest in the generation of mixed-valence phthalocyanine species prompted us to investigate the electrochemistry and spectroelectrochemistry of binuclear and tetranuclear zinc phthalocyanines.

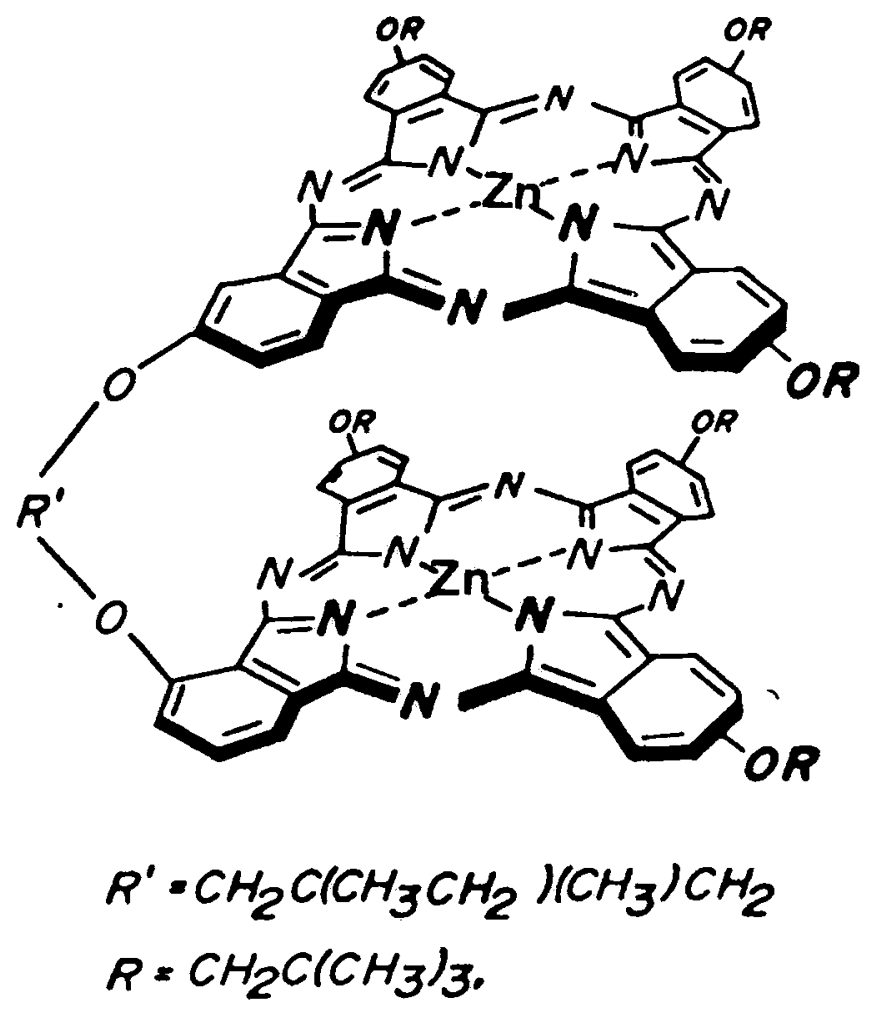

Recently we reported the electrochemistry and spectroelectrochemistry of a series of binuclear dicobalt phthalocyanines linked by bridges of one, two, four or five atoms, ${ }^{20}$ and of a tetranuclear phthalocyanine. ${ }^{21}$ No splitting of the redox couples was observed, the redox processes occurring via two one-electron transfers, at the same potential, at each phthalocyanine unit. In contrast, the analogous zinc derivatives of the five atom linked (clamshell) (1) and the tetranuclear phthalocyanine (2) show splitting of the first oxidation couple, and permit the observation of mixedvalence ring oxidized species. This is the first report of the spectroscopic characteristics of mixed-valence ring-oxidized species in binuclear dimetallic phthalocyanines. 


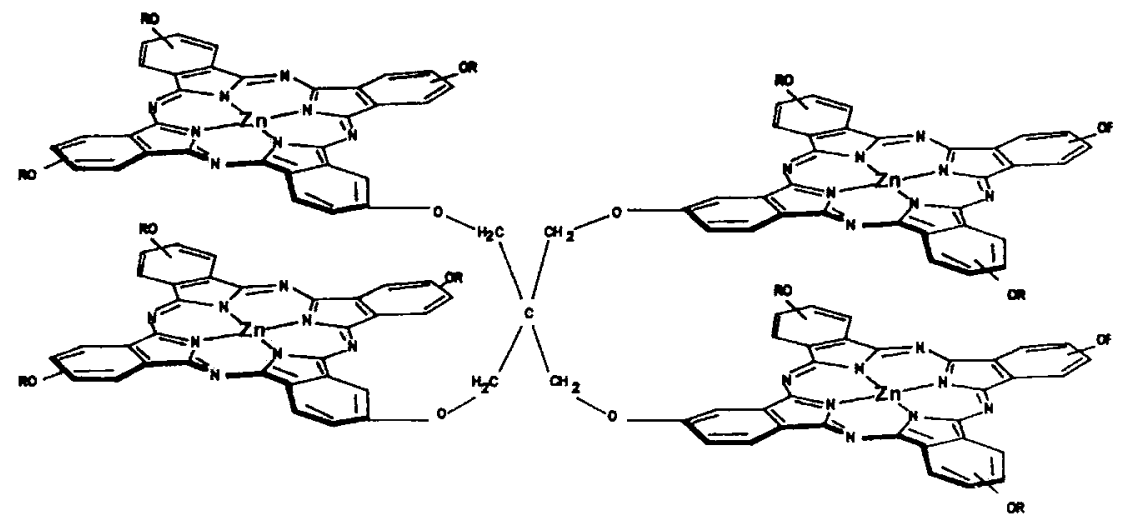

Electrochemical data for mononuclear $\mathrm{ZnPc}$ species have been reported in the literature. ${ }^{2-26} \mathrm{ZnPc}$ undergoes oxidation at the ring rather than at the metal centre, resulting in the formation of a phthalocyanine $\pi$-cation radical. This has also been prepared by chemical oxidation using thionyl chloride, bromine ${ }^{7}$ or iron(III) perchlorate. ${ }^{27}$ Recently Nyokong et al. ${ }^{26,28}$ have reported the optical and MCD spectra of the cation radical, $[\mathrm{ZnPc}(-1)]^{+}$. Octacyanosubstituted zinc phthalocyanine, $(\mathrm{CN})_{8} \mathrm{PcZn}$, exhibits four reversible, one-electron reduction steps which correspond to the formation of the mono-, di, tri, and tetra- anion. ${ }^{25,29}$

\section{EXPERIMENTAL}

\section{Materials}

Tetrabutylammonium perchlorate (TBAP, Kodak) was recrystallized from absolute ethanol and dried in a vacuum oven at $60^{\circ} \mathrm{C}$ for two days. 1,2-Dichlorobenzene (DCB, Aldrich, Gold Label), and $N, N$-dimethylformamide (DMF, Aldrich, anhydrous Gold Label) were used as supplied.

\section{Methods}

Electronic spectra were recorded with a Hitachi Perkin-Elmer Microprocessor 340 spectrometer. Cyclic and differential pulse voltammetry were performed with a Princeton Applied Research (PARC) 174A Polarographic Analyzer coupled to a PARC 175 Universal programmer. Electrochemical data were recorded under an atmosphere of argon, or nitrogen, using a conventional three electrode cell. A platinum disk described by the cross-sectional area of a 27-gauge wire (area $\sim 10^{-3} \mathrm{~cm}^{2}$ ), sealed in glass, was used as the working electrode, a platinum wire served as the counter electrode, and a $\mathrm{Ag} / \mathrm{AgCl}$ reference electrode $(-0.045 \mathrm{~V} v s$ $\mathrm{SCE})^{30}$ (in sat. $\mathrm{KCl}$ separated by a frit) corrected for junction potentials by being referenced internally to the ferrocenium/ferrocene $\left(\mathrm{Fc}^{+} / \mathrm{Fc}\right)$ couple $(0.31 \mathrm{~V}$ vs SCE). ${ }^{30-32}$ All DMF solutions were prepared and measurements made under an atmosphere of nitrogen within a Vacuum Atmospheres Drilab. The DCB solutions were prepared in air, degassed by purging with $\mathrm{N}_{2}$ gas and the measurements were carried out in a glove bag filled with an atmosphere of dry $\mathrm{N}_{2}$. 
The stability of the $\mathrm{Ag} / \mathrm{AgCl} / \mathrm{Cl}^{-}$electrode was checked using a solution of ferrocene in DCB; it was stable for at least two days. In various experiments involving $\mathrm{DMF}$ solutions, the $\mathrm{Fc}^{+} / \mathrm{Fc}$ couple was seen to lie in the range $+0.35-0.45 \mathrm{~V}$ vs $\mathrm{Ag}$ / $\mathrm{AgCl} / \mathrm{Cl}^{-}$, due to variations in junction potentials. In $\mathrm{DCB}$, the $\mathrm{Fc}^{+} / \mathrm{Fc}$ couple was observed at approximately $0.59 \mathrm{~V}$ ws $\mathrm{Ag} / \mathrm{AgCl} / \mathrm{Cl}^{-}$.

Spectroelectrochemical measurements were made with a $0.1 \mathrm{~cm}$ path length optically transparent electrode cell ${ }^{\mathbf{3 3}}$ utilizing a $\mathrm{Pt}$ minigrid, in conjunction with the Hitachi Perkin-Elmer spectrometer. A platinum flag, used as the counter electrode, was separated from the working compartment by a medium glass frit and a $\mathrm{Ag} / \mathrm{AgCl}$ reference electrode. Controlled potential electrolysis was carried out using a PARC $173 / 179$ potentiostat. Solutions were continuously purged with argon throughout the experiment. Solutions for electrochemistry or spectroelectrochemistry contained $0.1-$ $0.2 \mathrm{M}$ or $0.3 \mathrm{M}$ TBAP, respectively, as supporting electrolyte.

Electron spin resonance data were obtained using a Varian E4 spectrometer calibrated with diphenylpicrylhydrazide. Esr spectra of electrochemically generated $[\mathrm{ZnTrNPc}]_{4}$ species were obtained by bulk electrolysis of a solution (degassed by freeze-pump-thaw cycles) under an atmosphere of nitrogen in the dry box, and transferring the species to sealable esr tubes. The electronic spectra of these solutions were also recorded. The bulk electrolysis cell consisted of a platinum plate working electrode, a platinum flag counter, electrode, and a silver wire quasi-reference electrode. Counter and reference electrodes were separated from the working compartment by medium glass frits.

Solutions for aggregation studies were prepared by dilution of a freshly prepared stock solution of phthalocyanine. Spectra were recorded immediately after each dilution and solutions were shielded from room light to minimize any photochemical decomposition of phthalocyanine.

\section{Synthesis}

The synthetic procedures give rise to mixtures of isomers in which the neopentoxy groups are randomly distributed about the phthalocyanine ring. For ease of description we describe the syntheses of specifically defined isomers. 2,9,16,23Tetraneopentoxyphthalocyaninatozinc $(\mathrm{ZnTNPc})$ and the metal free phthalocyanines 1,3-bis-2'-(9,16,23-trineopentoxyphthalocyaninoxy)-2-ethyl-2-methylpropane $\left(\operatorname{EtMeO}(5)\left[\mathrm{H}_{2} \mathrm{TrNPc}\right]_{2}\right)$ and tetrakis $[((9,16,23$-trineopentoxyphthalocyanin-2-yl)oxy)methyl]methane $\left(\left[\mathrm{H}_{2} \mathrm{TrNPc}\right]_{4}\right)$ were prepared according to literature methods. ${ }^{21,34}$

\section{1,3-bis-2'-(9,16,23-trineopentoxyphthalocyaninoxyzinc)-2-ethyl-2-methylpropane (EtMeO(5)-[ZnTrNPc $]_{2}$}

A mixture of $\mathrm{EtMeO}(5)\left[\mathrm{H}_{2} \mathrm{TrNPc}_{2}(32 \mathrm{mg}, 0.019 \mathrm{mmol})\right.$, zinc acetate $(125 \mathrm{mg}$, $0.068 \mathrm{mmol}), 2$-methoxy-ethanol $\left(5 \mathrm{~cm}^{3}\right)$ and toluene $\left(10 \mathrm{~cm}^{3}\right)$ was heated at $120^{\circ} \mathrm{C}$ for 16 hours under an argon atmosphere. The solution was cooled and the product purified by flash chromatography using a column packed with silica gel following direct application of the mixture to the column. The column was eluted with toluene and the bluish green band collected. The solid isolated on evaporation of toluene was washed with methanol to give a bluish green product $(26.9 \mathrm{mg} ; 79 \%$ yield). MS, m/e: $1786.7 \mathrm{M}^{+}(100 \%)$. Anal.; Calcd. for $\mathrm{C}_{100} \mathrm{H}_{102} \mathrm{~N}_{16} \mathrm{O}_{8} \mathrm{Zn}_{2}: \mathrm{C}, 67.22 ; \mathrm{H}, 5.75 ; \mathrm{N}$, 12.54; $\mathrm{Zn}, 7.32 \%$. Found: $\mathrm{C}, 68.1 ; \mathrm{H}, 6.2 ; \mathrm{N}, 12.9 ; \mathrm{Zn}, 7.4 \%$. 
Tetrakis[((9,16,23-trineopentoxyphthalocyanin-2-yl)oxyzinc) methyl]methane ( $\left.[\mathrm{ZnTrNPc}]_{4}\right)$

A mixture of $\left[\mathrm{H}_{2} \mathrm{TrNPc}\right]_{4}(38 \mathrm{mg}, 0.012 \mathrm{mmol}), \mathrm{Zn}(\mathrm{OAc})_{2}(94.3 \mathrm{mg}, 0.51 \mathrm{mmol}), 2-$ methoxyethanol $\left(4 \mathrm{~cm}^{3}\right)$, and toluene $\left(8 \mathrm{~cm}^{3}\right)$ was heated at $120^{\circ} \mathrm{C}$ for 18 hours under an argon atmosphere. The solution was cooled and the product purified by flash chromatography using a column packed with silica gel following direct application of the mixture to the column. The mixture was eluted with toluene and the bluish green band collected. The solvent was evaporated to yield a dark blue solid $(33 \mathrm{mg}, 80 \%$ yield). MS, m/e: $3473.2 \mathrm{M}^{+}(100 \%)$. Anal.; Calcd. for $\mathrm{C}_{193} \mathrm{H}_{188} \mathrm{~N}_{32} \mathrm{O}_{16} \mathrm{Zn}_{4}: \mathrm{C}$, $66.74 ; \mathrm{H}, 5.46 ; \mathrm{N}, 12.91 ; \mathrm{Zn}, 7.53 \%$. Found: C, 67.6; H, 6.1; N, 12.0; Zn 7.0\%. Some analyses are not as close to theory as one would prefer; there are well known difficulties in analysing phthalocyanines. However, the mass spectra provide additional confirmatory evidence for molecular formulae.

TABLE I

Effect of addition of TBAP upon aggregation of EtMeO(S)[ZnTrNPc $]_{2}$ in DCB, with comparative data for ZnTNPc.

\begin{tabular}{lcc}
\hline EtMeO(5)[ZnTrNPc] ${ }_{2} \mathrm{M}$ & {$[\mathrm{TBAP}] \mathrm{M}$} & $\mathrm{A}_{680} / \mathrm{A}_{630}{ }^{\mathrm{a}}$ \\
\hline $4.72 \times 10^{-5}$ & 0 & 1.43 \\
& 0.12 & 1.60 \\
$5.67 \times 10^{-6}$ & 0.29 & 1.74 \\
& 0 & 1.46 \\
\hline $\mathrm{ZnTNPc}]$ & 0.29 & 1.84 \\
\hline $1.03 \times 10^{-5}$ & & $\mathrm{~A}_{680} / \mathrm{A}_{614^{2}}$ \\
\hline
\end{tabular}

${ }^{a}$ Absorbances at 614 and $680 \mathrm{~nm}$ are proportional to the monomer concentration, while absorbance at $630 \mathrm{~nm}$ is proportional to the degree of intramolecular (binuclear complex) or intermolecular (aggregation) coupling.

\section{RESULTS AND DISCUSSION}

\section{Aggregation Studies}

Electrochemical studies of phthalocyanines are usually complicated by aggregation in solution to form dimers and higher aggregates. For example, in the cyclic voltammograms (CV) of metallooctacyanophthalocyanines the first one-electron reduction consists of overlapping waves due to monomeric and aggregated reactants, ${ }^{25,29}$ while aggregation of the tetranuclear $[\mathrm{CoTrNPc}]_{4}$ complex in solution causes poorly defined waves. ${ }^{21}$ When aggregation occurs a band at around $630 \mathrm{~nm}$ arises in the electronic spectrum, as a result of the intermolecular interaction (exciton coupling ${ }^{35}$ ) between the phthalocyanine units. ${ }^{36,37}$ In binuclear or tetranuclear metallophthalocyanines, intramolecular coupling between the rings also causes a band at around $630 \mathrm{~nm}^{21,36}$ Both ZnTNPc and EtMeO(5)[ZnTrNPc $]_{2}$ in DCB solution obey Beer's 
law up to concentrations of $2 \times 10^{-4} \mathrm{M}$ and $9.4 \times 10^{-5} \mathrm{M}$ respectively. Thus there is no significant aggregation in these systems at the concentrations employed in electrochemical studies. Aggregation studies on the corresponding Co systems ${ }^{36}$ show deviation from Beer's law for the $Q$ band at concentrations an order of magnitude lower than for the zinc system.

The addition of TBAP to $\mathrm{EtMeO}(5)[\mathrm{ZnTrNPc}]_{2}$ in DCB increases the relative intensity of the $680 \mathrm{~nm}$ to the $630 \mathrm{~nm}$ band. The ratio $\left(\mathrm{A}_{680} / \mathrm{A}_{630}\right)$ increases by a constant percentage over an order of magnitude concentration range of the phthalocyanine in DCB (Table I), in the regime where intermolecular aggregation does not occur. Thus TBAP causes a decrease in the intramolecular coupling between the phthalocyanine rings. There is no significant change in the relative intensity of the $680 \mathrm{~nm}$ to the vibrational $614 \mathrm{~nm}$ band $\left(\mathrm{A}_{680} / \mathrm{A}_{614}\right)$ in mononuclear ZnTNPc in $\mathrm{DCB}$, upon additon of TBAP at a concentration at which only monomeric $\mathrm{ZnTNPc}$ is present, and therefore no formation of aggregates which would have decreased the $680 \mathrm{~nm}$ absorption while increasing absorption in the $614-630 \mathrm{~nm}$ region. This is in contrast to the CoTNPc data, where the addition of electrolyte (TBAP) was found to greatly increase the aggregation of the molecules. ${ }^{21,36}$

TABLE II

Electrochemical data for mononuclear, binuclear and tetranuclear zinc neopentoxyphthalocyanine complexes. $^{\mathrm{a}}$

\begin{tabular}{|c|c|c|c|c|}
\hline \multirow[b]{2}{*}{ System/Couple } & \multicolumn{4}{|c|}{$\mathrm{E}_{\mathrm{1}, 2 / \mathrm{V}} \mathrm{Ep} / \mathrm{mV}$} \\
\hline & \multicolumn{2}{|c|}{ DCB Solution } & \multicolumn{2}{|c|}{ DMF Solution } \\
\hline \multicolumn{5}{|l|}{ ZnTNPc } \\
\hline $\operatorname{Pc}(0) / \operatorname{Pc}(-1)$ & 0.64 & & & \\
\hline $\mathrm{Pc}(-1) / \mathrm{Pc}(-2)$ & -0.02 & 70 & 0.00 & 60 \\
\hline $\mathrm{Pc}(-2) / \mathrm{Pc}(-3)$ & -1.66 & 75 & -1.43 & 95 \\
\hline $\mathrm{Pc}(-3) / \mathrm{Pc}(-4)$ & -2.04 & & -1.85 & 70 \\
\hline $\begin{array}{l}\mathrm{EtMeO}(5)[\mathrm{ZnTrNPc}]_{2} \\
{[\mathrm{Pc}(0)]_{2} /[\mathrm{Pc}(-1)]_{2}}\end{array}$ & $\mathrm{EtMeO}(5)[\mathrm{ZnTrNPc}]_{2}$ & & & \\
\hline$[\mathrm{Pc}(-1)]_{2} /[\mathrm{Pc}(-1) \cdot \operatorname{Pc}(-2)]$ & 0.00 & $(50)$ & 0.18 & $(50)$ \\
\hline$[\mathrm{Pc}(-1)] \cdot \mathrm{Pc}(-2)] /[\mathrm{Pc}(-2)]_{2}$ & -0.08 & (55) & 0.03 & (50) \\
\hline$[\mathrm{Pc}(-2)]_{2} /[\mathrm{Pc}(-3)]_{2}$ & -1.68 & 80 & -1.44 & 60 \\
\hline$[\mathrm{Pc}(-3)]_{2} /[\mathrm{Pc}(-4)]_{2}$ & -2.12 & & -1.87 & 60 \\
\hline \multicolumn{5}{|l|}{$\left[\mathrm{ZnTr} \mathrm{NPc}_{4}\right.$} \\
\hline$[\mathrm{Pc}(-1)]_{4} /[\mathrm{Pc}(-1) \cdot \operatorname{Pc}(-2)]_{2}$ & 0.04 & $(60)$ & 0.18 & $(50)$ \\
\hline$[\mathrm{Pc}(-1) \cdot \mathrm{Pc}(-2)]_{2} /[\mathrm{Pc}(-2)]_{4}$ & -0.07 & $(50)$ & 0.03 & $(40)$ \\
\hline$[\mathrm{Pc}(-2)]_{4} /[\mathrm{Pc}(-3)]_{4}$ & -1.64 & 70 & -1.44 & 50 \\
\hline$[\mathrm{Pc}(-3)]_{4} /[\mathrm{Pc}(-4)]_{4}$ & -2.13 & 80 & -1.86 & 60 \\
\hline
\end{tabular}

${ }^{a}$ Solutions contain $0.1-0.2 \mathrm{M}$ TBAP. Potentials are reported with respect to the ferrocenium/ferrocene couple. $E_{1,2}$ values measured by cyclic voltammetry at 100,50 and $20 \mathrm{mV} / \mathrm{s}\left[\mathrm{E}_{1 / 2}=\left(\mathrm{E}_{\mathrm{pa}}+\mathrm{E}_{\mathrm{pc}}\right) / 2\right]$ or differential pulse voltammetry at $2 \mathrm{mV} / \mathrm{s}$ gave essentially identical potentials. Values of $\mathrm{E}_{\mathrm{p}}\left(=\mathrm{E}_{\mathrm{pa}}-\mathrm{E}_{\mathrm{pc}}\right)$ are given for a potential sweep rate of $20 \mathrm{mV} / \mathrm{s}$. Data in parentheses are estimated from overlapping waves. Half-wave potentials in $\mathrm{DCB}$ versus $\mathrm{Ag} / \mathrm{AgCl} / \mathrm{Cl}^{-}$correspond approximately with the above DCB data plus $0.59 \mathrm{~V}$. 


\section{Electrochemistry}

The cyclic voltammetry of ZnTNPc in DCB or DMF gave two oxidation and two reduction couples within the potential limits of the solvent studied, corresponding to the first and second oxidations and reductions, respectively, of the phthalocyanine ring. In the case of EtMeO(5)[ZnTrNPc $]_{2}$ and $[\mathrm{ZnTrNPc}]_{4}$ in DCB or DMF, three oxidation and two reduction couples were observed. A summary of the half-wave potentials and the peak-to-peak separation of each wave is given in Table II. In the case of $\mathrm{ZnTNPc}$, the peak at $\sim 0.0 \mathrm{~V}\left(v \mathrm{Fc}^{+} / \mathrm{Fc}\right.$ ), corresponds to the oxidation of the phthalocyanine ligand, forming $\left[\mathrm{Zn}^{\mathrm{II}} \mathrm{TNPc}(-1)\right]^{+}$. Similarly, in the binuclear and tetranuclear phthalocyanine cases, the double peaks at $\sim 0.0 \mathrm{~V}\left(v s \mathrm{Fc}^{+} / \mathrm{Fc}\right)$ also correspond to the oxidation of the phthalocyanine ligand. These narrowly separated waves are shown in Fig. 1 together with the CV of the mononuclear phthalocyanine for comparison. Controlled potential electrochemistry (see below) confirms that

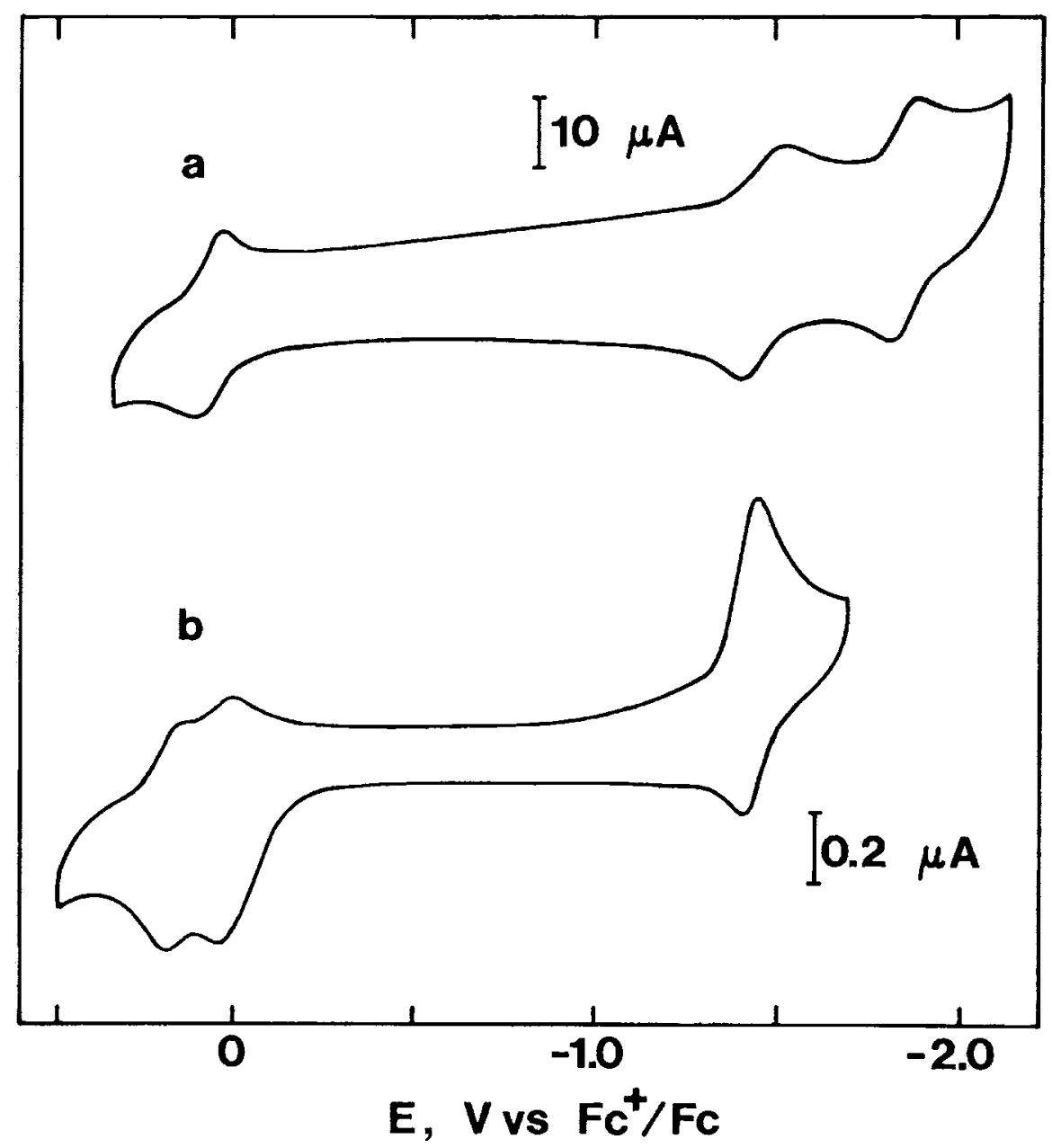

FIGURE 1 Cyclic voltammograms of (a): the first oxidation, and first and second reduction waves of ZnTNPc (scan speed $=100 \mathrm{mV} / \mathrm{s}$ ); (b): first and second oxidation and first reduction waves of [ZnTrNPc] (scan speed $50 \mathrm{mV} / \mathrm{s}$ ). All are in DMF solution containing $0.1-0.2 \mathrm{M}$ TBAP. The phthalocyanine concentrations are $\sim 1 \times 10^{-4} \mathrm{M}$. 


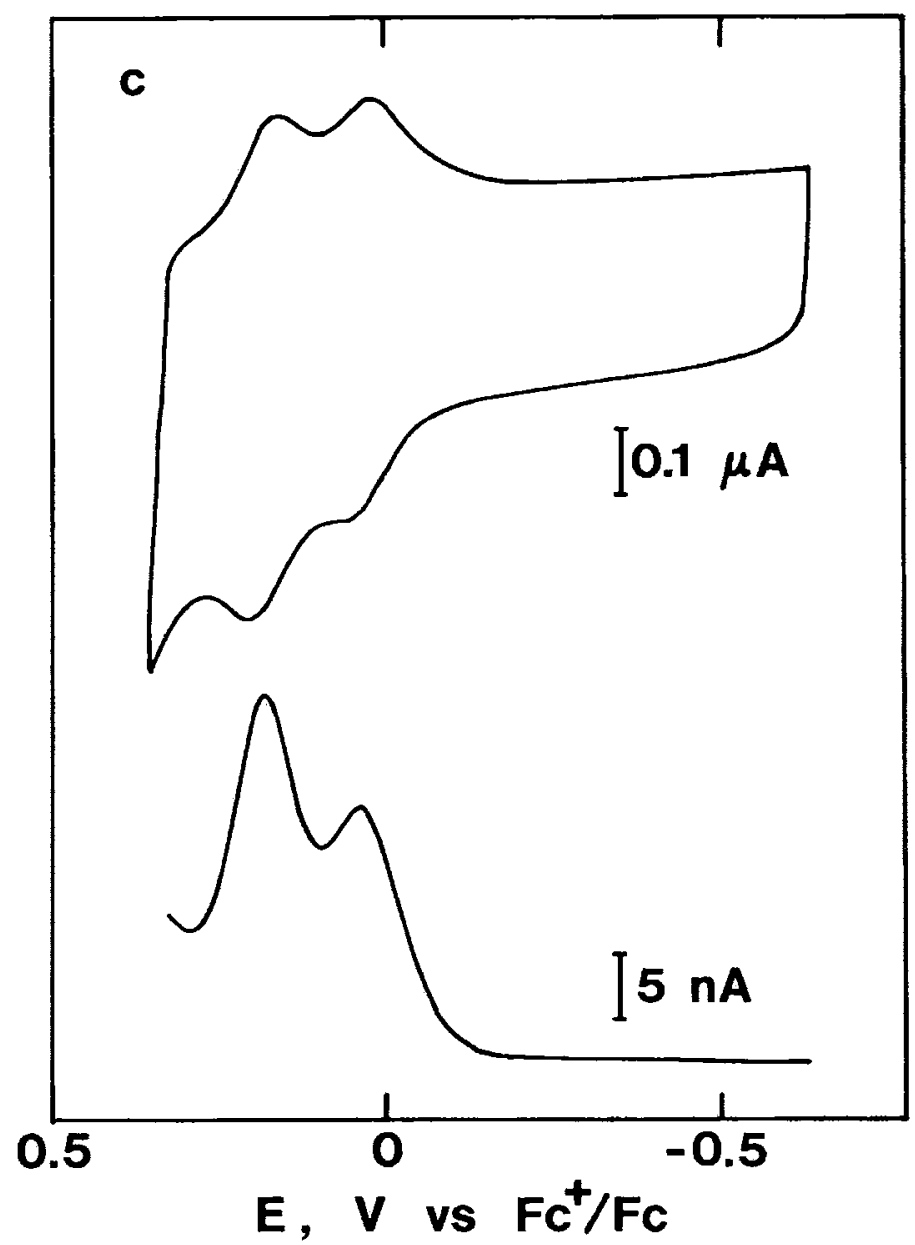

FIGURE 1 (cont.) (c): cyclic $(200 \mathrm{mV} / \mathrm{s})$ and differential pulse $(2 \mathrm{mV} / \mathrm{s})$ voltammograms of the first and second oxidation of EtMeO(5)[ZnTrNPc] $]_{2}$. All are in DMF solution containing 0.1-0.2 M TBAP. The phthalocyanine concentrations are $\sim 1 \times 10^{-4} \mathrm{M}$.

these two waves arise from the stepwise oxidation of the two phthalocyanine rings, or two pairs of rings, of the same molecule. The separation between these waves increases in DMF solution (150 and $80 \mathrm{mV}$ in DMF and DCB respectively for EtMeO(5) $[\mathrm{ZnTrNPc}]_{2}$ ) and clearly resolved $\mathrm{CV}$ and differential pulse voltammetry (DPV) curves are obtained (Fig. 1). Although the anodic to cathodic peak separation is difficult to determine accurately, the estimated values are close to $59 \mathrm{mV}$ and $\mathrm{i}_{\mathbf{p}}$ is proportional to $\mathrm{v}^{1 / 2}$ thus confirming a diffusion-controlled one-electron transfer step.

No splitting was observed in the other redox peaks and the potentials of these redox couples are in close agreement for the mononuclear, binuclear and tetranuclear systems. Thus, there is no stabilization of mixed valence anion radical species. Although the half-wave potentials of ZnTNPc in DMF are different from those of $\mathrm{ZnPc}(\mathrm{Im})(\mathrm{Im}=$ imidazole $)$ and $\mathrm{ZnPc}(\mathrm{Py})(\mathrm{Py}=$ pyridine $)$ complexes, ${ }^{26}$ the separation between the oxidation and reduction couples is the same. The redox potentials of $\mathrm{ZnPc}(\mathrm{Im})$ are about $200 \mathrm{mV}$ more positive than those of $\mathrm{ZnTNPc}$ in DMF, possibly a consequence of the difference in the coordinating abilities of the solvent and the axial ligands. 


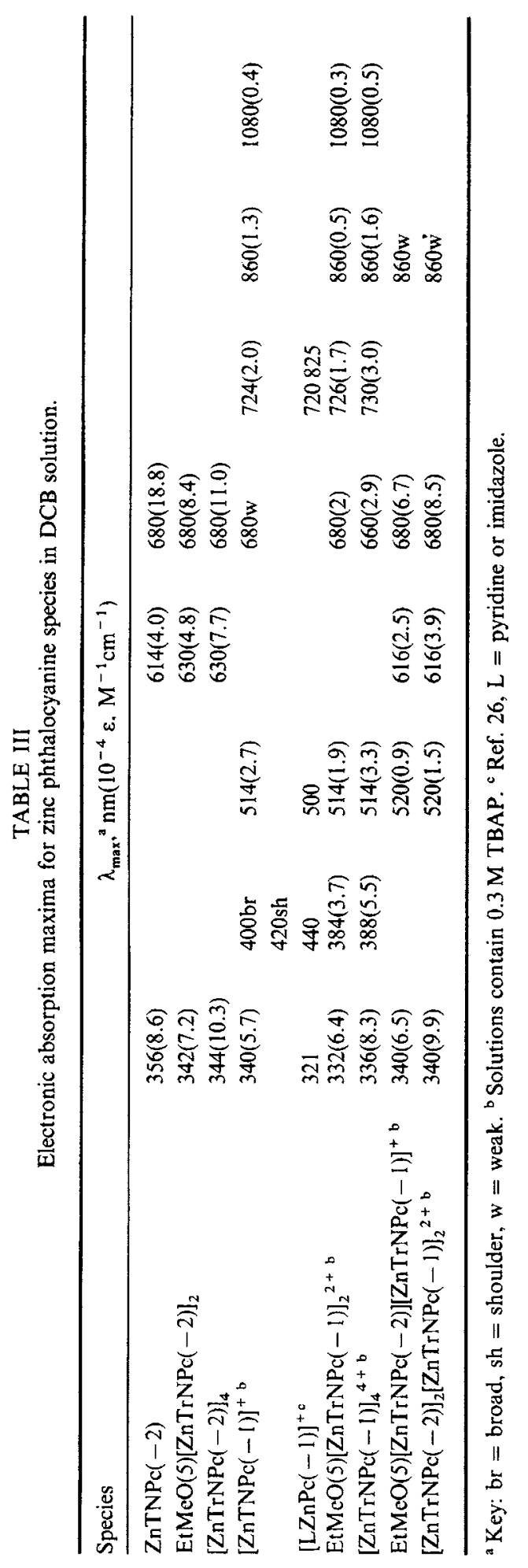



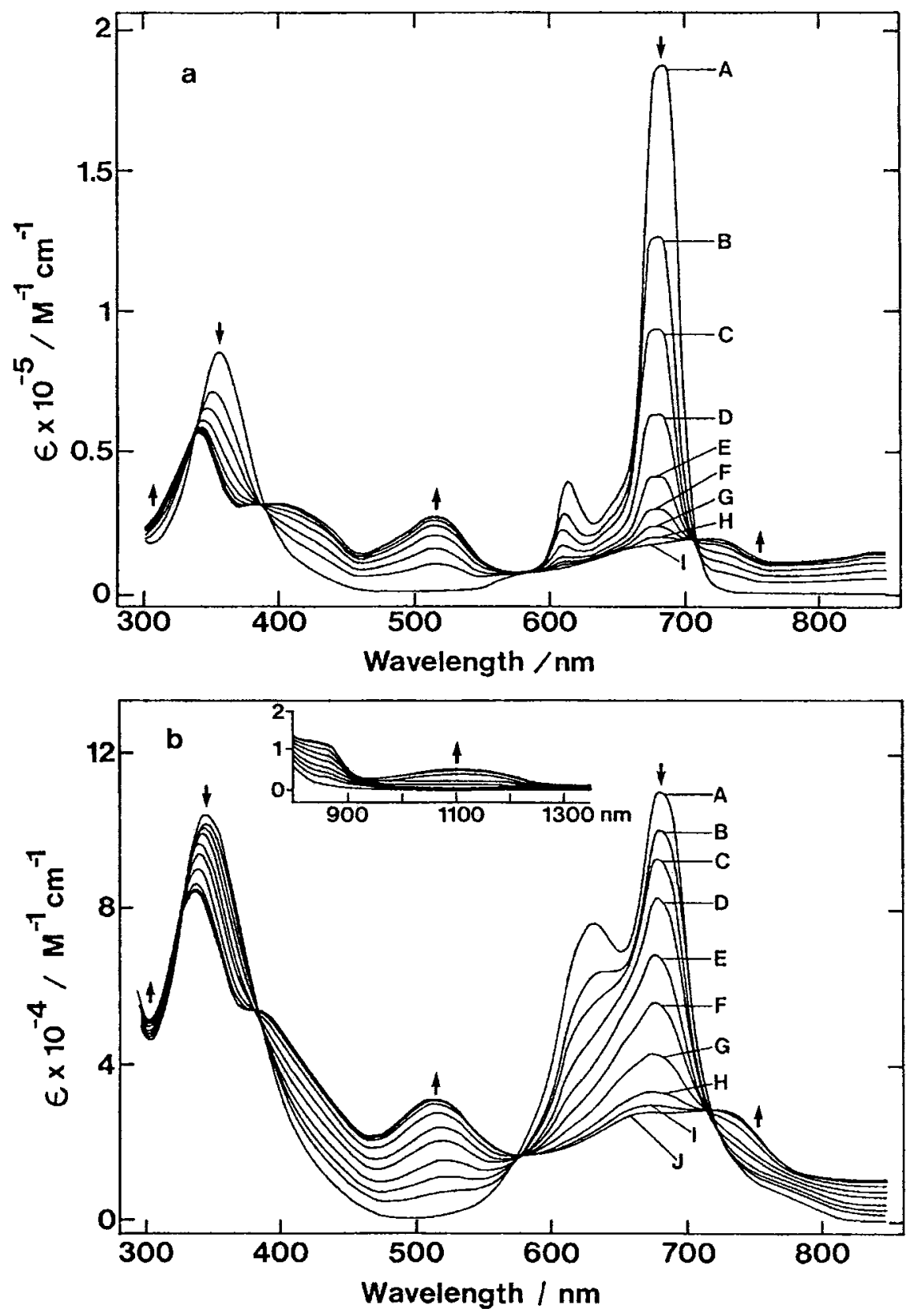

FIGURE 2 Controlled potential spectroelectrochemistry, (a): ZnTNPc in DCB solution showing the development of the radical cation $[\operatorname{ZnTNPc}(-1)]^{+}$as the potential is stepped through the first oxidation wave; A: $0 \mathrm{~V}, \mathrm{~B}: 0.50 \mathrm{~V} ; \mathrm{C}: 0.52 \mathrm{~V} ; \mathrm{D}: 0.54 \mathrm{~V} ; \mathrm{E}: 0.56 \mathrm{~V} ; \mathrm{F}: 0.58 \mathrm{~V} ; \mathrm{G}: 0.60 \mathrm{~V} ; \mathrm{H}: 0.62 \mathrm{~V} ; \mathrm{I}: 0.70 \mathrm{~V}$ vs $\mathrm{Ag} / \mathrm{AgCl} ;[\mathrm{ZnTNPc}]=1.1 \times 10^{-4} \mathrm{M} ;(\mathrm{b}):[\mathrm{ZnTrNPc}]_{4}$ in DCB solution showing the development of the MVS and fully oxidized species as the potential is stepped through the first two oxidation waves; $\mathrm{A}: 0 \mathrm{~V} ; \mathrm{B}$ : $0.45 \mathrm{~V} ; \mathrm{C}: 0.48 \mathrm{~V} ; \mathrm{D}: 0.51 \mathrm{~V} ; \mathrm{E}: 0.55 \mathrm{~V} ; \mathrm{F}: 0.58 \mathrm{~V} ; \mathrm{G}: 0.62 \mathrm{~V} ; \mathrm{H}: 0.66 \mathrm{~V} ; \mathrm{I}: 0.70 \mathrm{~V} ; \mathrm{J}: 0.75 \mathrm{~V}$ vs Ag/AgCl; $\left[(\mathrm{ZnTrNPc})_{4}\right]=3.2 \times 10^{-5} \mathrm{M}$. These data are used for the analyses in Figs. 5 and 6 . Note that the initial spectrum is that of the unoxidized SS species, while the final spectrum is that of the fully oxidized OxOx species. The solutions contain $c a 0.3 \mathrm{M}$ TBAP. 


\section{Spectroelectrochemistry}

Stepwise controlled potential oxidation of a solution of ZnTNPc in DCB results in the spectroscopic changes shown in Fig. 2a and a change in solution colour from bluish green to pink. Isosbestic points are observed at 338, 388, 580 and $708 \mathrm{~nm}$. Spectroscopic data are given in Table III. The final spectrum has a similar appearance to other phthalocyanine $\pi$-cation radical species spectra ${ }^{2,9,20,21,23,38-45}$ and agrees fairly closely with the absorption spectrum of the $[\mathrm{ZnPc}(-1)]^{+}$species reported by Nyokong et al. ${ }^{26}$

The presence of a split electrochemical wave for the oxidation process in the biand tetranuclear systems, implies the existence of a mixed valence species (MVS), ${ }^{46}$ whose spectrum may be obtained by oxidizing the species stepwise through this pair of electrochemical waves. Such data for a solution of $[\mathrm{ZnTrNPc}]_{4}$ in DCB are shown in Fig. 2b. Similar spectroscopic changes were observed following the stepwise oxidation of EtMeO(5) $[\mathrm{ZnTrPc}]_{2}$ along its first and second oxidation waves. For the tetranuclear species, isosbestic points occur in the first stage of oxidation, to the MVS, at $328,384,580$ and $720 \mathrm{~nm}$, shifting to $328,380,580$ and $714 \mathrm{~nm}$ in the second stage oxidation. The final spectra (1-electron/phthalocyanine ring oxidized) of both the binuclear and tetranuclear species are similar to that of the oxidized mononuclear zinc phthalocyanine except for the absence of a broad band around $400 \mathrm{~nm}$ (see Table III).

A graphical analysis can be used to determine the number of species in solution from the spectroscopic data ${ }^{47}$ If the absorbance value of a particular solution, $j$, at a specific wavelength $i$, is denoted by $A_{i j}$, a plot of $A_{i j}-A_{i j}$ for a series of solutions, $j^{\prime}$, at wavelength $i$ vs the corresponding difference $A_{i i^{\prime}}-A_{i i^{\prime}}$ at another wavelength $i^{\prime}$ will give a straight line passing through the origin for each $i^{\prime}$ if only two species exist in solution. When the spectroelectrochemical data associated with ZnTNPc in DCB (Fig. 2a) are analyzed in this way an excellent straight line passing through the origin is obtained (Fig. 3a). In contrast, the spectroelectrochemical data for the binuclear

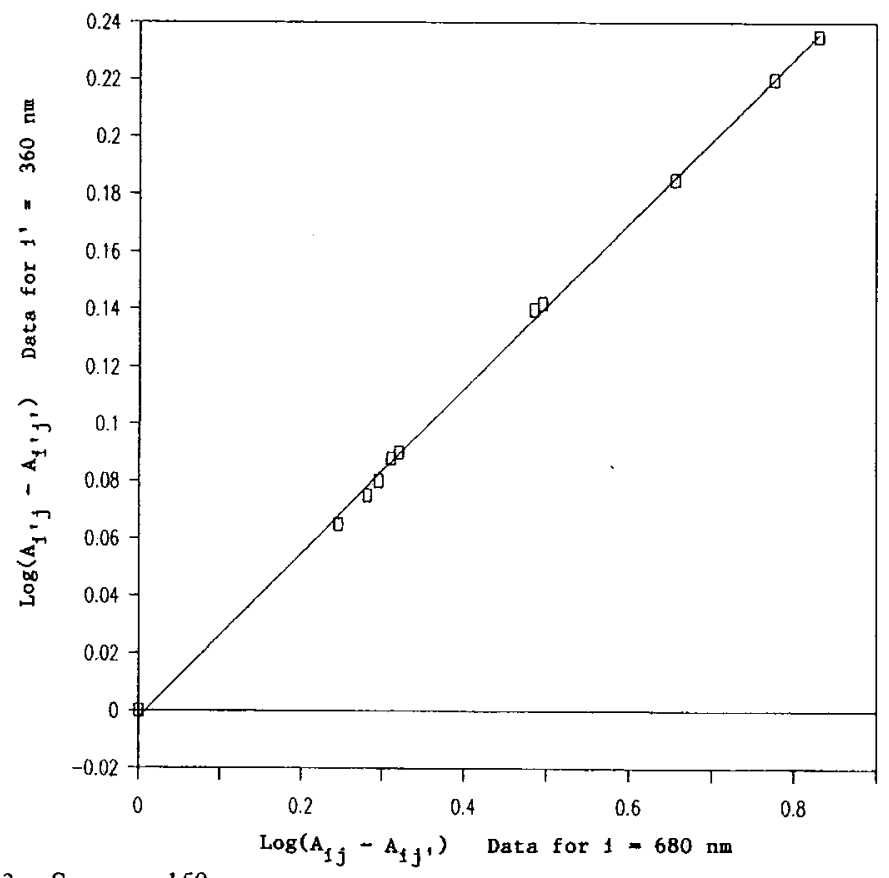

FIGURE 3. See page 150 
and tetranuclear systems fail to give a good straight line with the above analysis (shown for (2) in Fig. 3b), even though the presence of isosbestic points implies that the data are good; this suggests that more than two species are present in solution. In these cases the test for three species in solution is positive since plots of $\left(A_{2 j}-A_{2 j}\right) /$ $\left(\mathrm{A}_{1 \mathrm{j}}-\mathrm{A}_{\mathrm{ij}}\right)$ vs $\left(\mathrm{A}_{3 \mathrm{j}^{\prime}}-\mathrm{A}_{3 \mathrm{j}^{\prime}}\right) /\left(\mathrm{A}_{1 \mathrm{j}}-\mathrm{A}_{\mathrm{ij}^{\prime}}\right)$ give a straight line ((2) in Fig. 3c), where 1,2 and 3 are different wave-lengths and $j^{\prime}$ is a specific solution.

A nernstian plot of the spectroelectrochemical data associated with ZnTNPc in DCB over the first oxidation wave gives a slope of $58( \pm 1) \mathrm{mV}$, and an intercept at $\mathrm{E}_{1 / 2}$, in concordance with a one-electron process.

Nernstian plots of the spectroelectrochemical data over the first and second oxidation waves of EtMeO(5)[ZnTrNPc $]_{2}$ and $[\mathrm{ZnTrNPc}]_{4}$ are obtained by considering the oxidation of initial phthalocyanine (SS) to MVS and oxidation of MVS to the final product (OxOx) as two independent electrochemical steps. Assuming the potentials shown in Table II, the distribution of SS, MVS and OxOx is shown for (2) in DCB, in Fig. 4. Below about $0.53 \mathrm{~V}$, and above about $0.6 \mathrm{~V}$ there are essentially only two species in equilibrium. In these regions it is a reasonable approximation to plot $\log ([\mathrm{MVS}] /[\mathrm{SS}])$ and $\log ([\mathrm{OxOx}] /[\mathrm{MVS}])$, each, against potential, ${ }^{48}$ to obtain conventional two-species Nernstian plots. The results are shown in Fig. 5. The spectroscopically derived half-wave potentials are 0.50 and $0.62 \mathrm{~V}$ vs $\mathrm{Ag} / \mathrm{AgCl} / \mathrm{Cl}^{-}$ compared with the electrochemically derived 0.52 and $0.63 \mathrm{~V}$ respectively (Table II). The slope for the latter plot is in perfect agreement with expectation, while that of the former (with a lower regression coefficient) is slightly high. Nevertheless the data confirm that, mechanistically, these individual couples are one-electron processes. The Nernstian slopes (data not shown) for the binuclear system (1) are 69 and $55 \mathrm{mV}$ respectively.

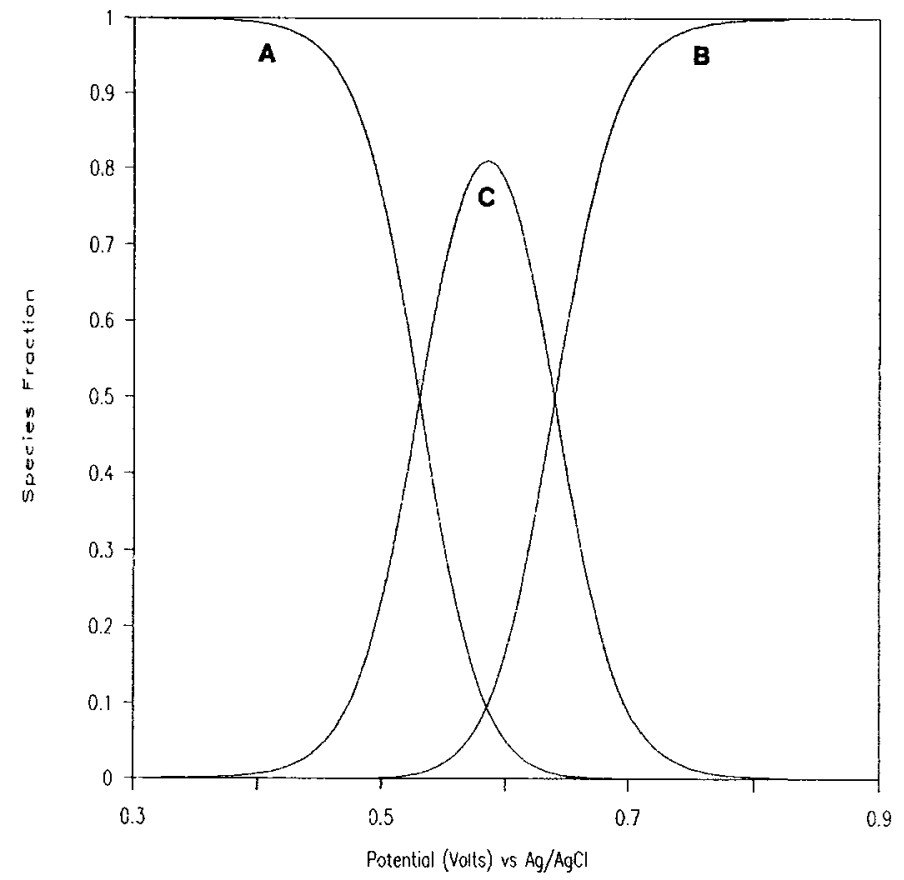

FIGURE 4 The fractional distribution of (A) SS, (B) OxOx and (C) MVS in DCB, using the half-wave potentials for [MVS]/[SS] and [OxOx]/[MVS] at 0.52 and $0.63 \mathrm{~V}$ vs $\mathrm{Ag} / \mathrm{AgCl} / \mathrm{Cl}^{-}$, respectively. 

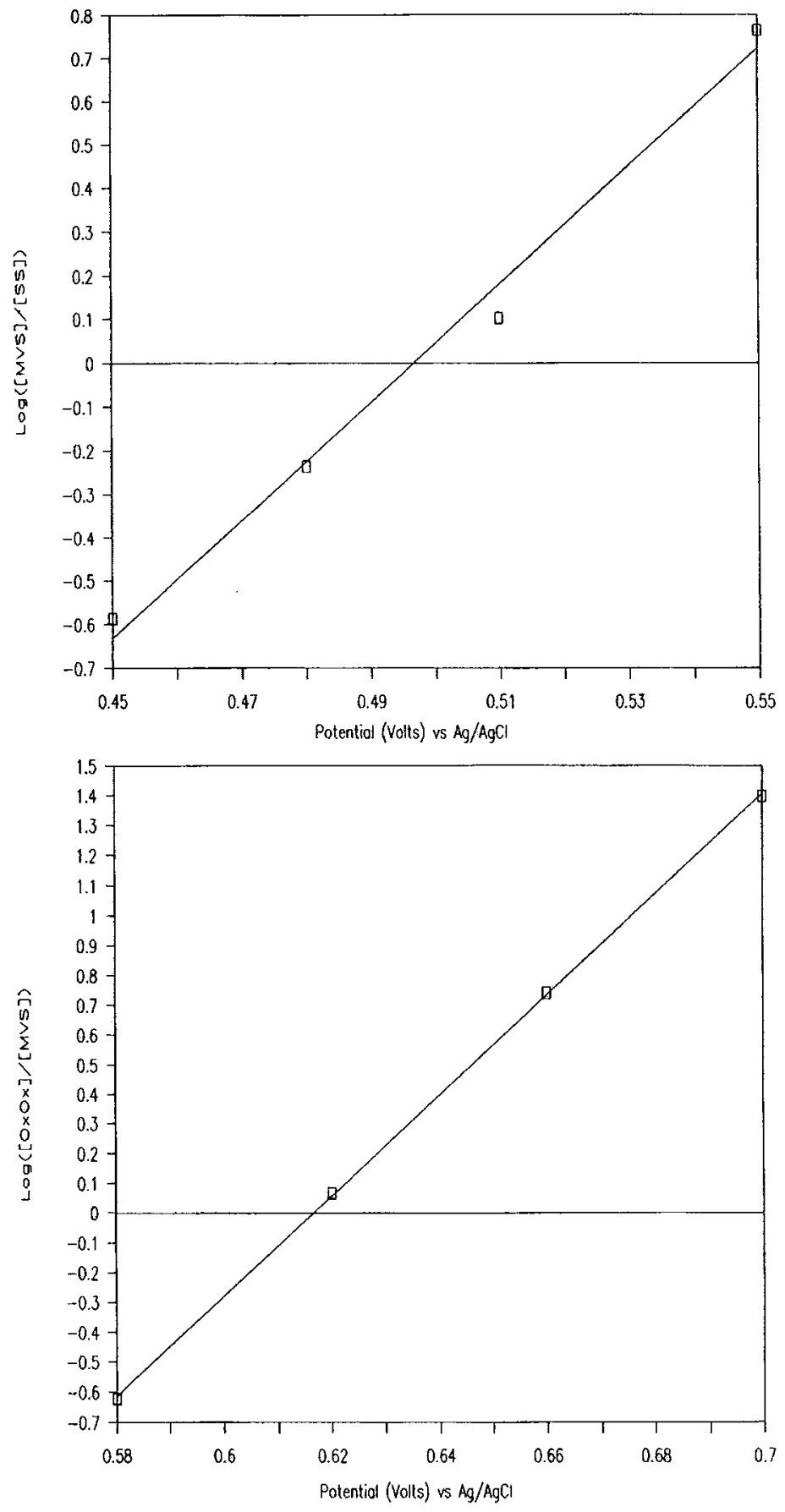

FIGURE 5 (a): A Nernstian plot of $\log \left([\mathrm{MVS}] /[\mathrm{SS}]\right.$ ) versus potential (vs $\mathrm{Ag} / \mathrm{AgCl} / \mathrm{Cl}^{-}$) for the MVS and SS components of the tetranuclear $[\mathrm{ZnTrNPc}]_{4}$ species (2) in DCB. The straight line is a least-squares line corresponding to $\mathrm{E}=0.50+0.74 \log ([\mathrm{MVS}] /[\mathrm{SS}]$ ) (in volts) with a regression coefficient of 0.990 ; (b): A Nernstian plot of $\log \left([\mathrm{OxOx}] /[\mathrm{MVS}]\right.$ ) versus potential (vs $\mathrm{Ag} / \mathrm{AgCl} / \mathrm{Cl}^{-}$) for the $\mathrm{OxOx}$ and $\mathrm{MVS}$ components of the tetranuclear $\left[\mathrm{ZnTrNPc}_{4}\right.$ species (2) in DCB. The straight line is a least-squares line corresponding to $\mathrm{E}=0.62+0.59 \log ([\mathrm{OxOx}] /[\mathrm{MVS}]$ ) (in volts) with a regression coefficient of 0.999 . 
A coulometric study of the double oxidation wave of the binuclear species (1) yields 2.08 electrons/molecule. Stopping the coulometry experiment in the centre of the double wave yielded approximately 1 electron/molecule though the two waves are too close together to obtain this number accurately.

Thus the reactions corresponding to the split oxidation waves in the voltammograms are one-electron processes. The observation of two sets of well defined isosbestic points, the splitting of the oxidation wave into two components in the cyclic voltammograms, and the coulometric and Nernstian analyses clearly indicate that for the binuclear zinc complex, oxidation of the phthalocyanine rings of each molecule occurs in two one-electron steps, while in the case of the tetranuclear system, oxidation occurs in two steps, each involving the simultaneous one-electron oxidation of a pair of phthalocyanine rings. Therefore the final oxidized product is formed via an intermediate species which contains ligands of mixed valencies.

Chemical oxidation of ZnTNPc to its $\pi$-cation radical can be achieved using either silver perchlorate or bromine, though in the former case, it appears impossible to achieve complete oxidation even with a very large excess of silver(I). On the other hand, bromine (in $\mathrm{CCl}_{4}$ ) can completely oxidize $\mathrm{ZnTNPc}$ to its cation radical when a two-fold excess is used. If a two-fold equivalent excess of bromine is added to $[\mathrm{ZnTrNPc}]_{4}$, the MVS species is formed. The electronic spectrum of this solution does not show bands at 388 and $730 \mathrm{~nm}$ and only a weak band at $1080 \mathrm{~nm}$, in agreement with the calculated spectrum of the MVS, (see below).

\section{Electronic spectra}

The electronic spectra of the bi- and tetranuclear zinc (OxOx) cation radical species differ from that of the mononuclear radical cation (compare Figs. $2 a$ and $2 b$ ), having a peak near $380 \mathrm{~nm}$ rather than broad absorption in the $380-440 \mathrm{~nm}$ range. Minor et al. ${ }^{49}$ first rationalized the spectra of phthalocyanine radical cations, while, more recently, Nyokong et al., ${ }^{28}$ assigned the various transitions of $[\operatorname{ZnPc}(-1)]^{+}$through analysis of its absorption and magnetic circular dichroism spectra. On these bases, the absorption band near $680-725 \mathrm{~nm}$ in all the OxOx radical cation species here discussed is assigned as the $\pi-\pi^{*} \mathrm{Q}$ band, and the 380 and $330 \mathrm{~nm}$ absorption as the Soret (B band) $\pi-\pi^{*}$ and $N \pi-\pi$ transitions as discussed in depth elsewhere. ${ }^{28}$ The bands near 520 and $860 \mathrm{~nm}$ are assigned as $\pi-\pi$ transitions to the $\mathrm{A}_{1 \mathrm{u}} \mathrm{HOMO}$, also in accordance with the assignment of Nyokong et al. ${ }^{28}$

\section{$M V S$ electronic spectra}

The absorption spectrum of the tetranuclear (2) MVS was calculated by deconvolution of the spectroelectrochemical data, using the distribution shown in Fig. 4. For maximum accuracy, the spectrum obtained at approximately the mid-point potential of the two waves, where the concentration of the MVS is at a maximum, was deconvoluted. The resulting MVS spectrum is shown in Fig. 6. When superimposed on Fig. 2b, the MVS spectrum (normalized to the same concentration) crosses through the isosbestic points, as is required. Similar data were obtained using the binuclear species.

The calculated spectrum of the MVS does not show bands at 388 and $730 \mathrm{~nm}$ whereas it exhibits all the other bands which appear in the fully oxidized cation (see Table III). In the near IR region the band at $1080 \mathrm{~nm}$ is very weak for the MVS but appears as a relatively strong (broad) band for the doubly oxidized species. 
The existence of the MVS implies some degree of electronic coupling between the unoxidized and oxidized rings. In the absence of such coupling, the electronic spectrum would be the simple mean of the oxidized and unoxidized species. Thus the difference between the observed MVS electronic spectrum and the calculated mean spectrum of the oxidized and unoxidized ring is a measure of the spectroscopic consequences of this electronic coupling. This difference spectrum is shown for species (2) in Fig. 6. There are small shifts observed in the Q and Soret regions and also a small shift in the characteristic radical cation band near $520 \mathrm{~nm}$. This provides further evidence of the unique character of the MVS.

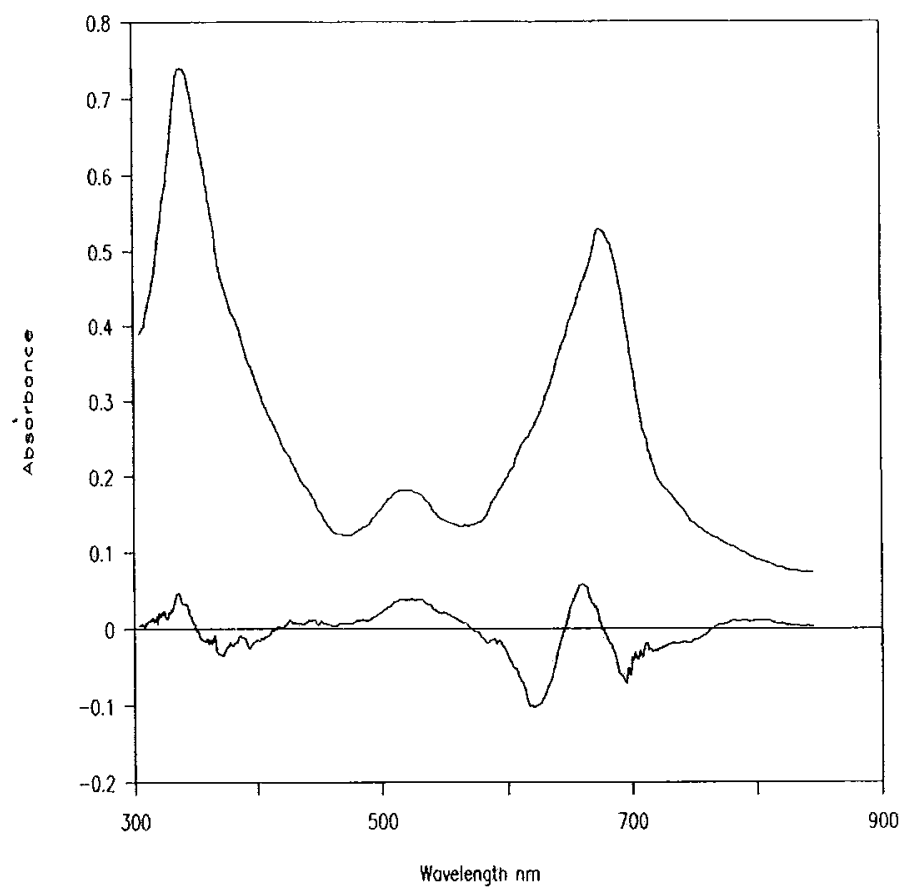

FIGURE 6 (Upper): The spectrum of the MVS of tetranuclear (2), in DCB, deconvoluted from data in Fig. 2b (see text); (Lower): The difference spectrum is the spectrum of the MVS from which the mean normalized spectrum of one oxidized and one unoxidized ring has been subtracted.

The band at $1080 \mathrm{~nm}$ is a candidate for an inter-valence (IT) transition given its typical IT characteristics being broad and in the near infrared region. However, it grows stronger after the mid-point of the spectroelectrochemical experiments where the concentration of the MVS must be declining. It is also present in the mononuclear complex $[\operatorname{ZnTNPc}(-1)]^{+}$. We conclude therefore that it is a hitherto previously unassigned $\pi-\pi$ transition of the radical cation. The anticipated IT band must be obscured by the strong and complex $\pi$-absorption of this MVS species. A band also appears in the near infrared region, at $\sim 1000 \mathrm{~nm}$, upon the one-electron ring oxidation of the mixed-valence lanthanide diphthalocyanine compounds, i.e., when $\left[\left(\mathrm{Pc}(-1)_{2} \mathrm{Ln}\right]^{+}\right.$is formed. ${ }^{10}$ Bands at $\sim 1000 \mathrm{~nm}$ have been reported previously for $\mathrm{LiPc}(-1),{ }^{44 \mathrm{~b}} \mathrm{CIMgPc}(-1), \mathrm{NO}_{3} \mathrm{CuPc}(-1)$ and $\mathrm{HPc}(-1){ }^{44 \mathrm{a}}$ 
The Soret region of the MVS is more symmetric than that of the fully oxidized species, presumably with both the $\mathrm{B}$ and $\mathrm{N}$ bands lying under the $340 \mathrm{~nm}$ band envelope.

\section{Electron Spin Resonance Data}

The EPR spectrum of a chemically oxidized solution of ZnTNPc in DCB recorded at $77 \mathrm{~K}$ gave an isotropic $\mathrm{g}$ value of 2.001 (1) with a peak-to-peak separation of $4 \mathrm{G}$, consistent with an unpaired electron delocalized over the organic fragment. No hyperfine structure was observed for this signal. In contrast, Myers et al. ${ }^{7}$ found that the oxidation of unsubstituted $\mathrm{ZnPc}$ gave a diamagnetic complex which was esr silent and therefore proposed a dimeric radical structure. In ZnTNPc the bulky substituents may prevent the $\pi$-clouds of the oxidized cation radical species from getting sufficiently close together. In addition, it was reported that $\mathrm{Zn}$ (tetra-4-t-butylPc), ${ }^{50}$ and $\mathrm{LZnPc}(\mathrm{L}=\mathrm{Im} \text { or } \mathrm{Py})^{26}$ on oxidation gave an esr signal characteristic of an organic free radical.

The absorption and esr spectra were recorded during stepwise oxidation of [ZnTrNPc $]_{4}$ in DCB following the first and second oxidation waves. On oxidation across the first wave, there is observed a $\pi$-cation radical esr signal whose intensity increases in parallel with the increase in absorbance at $520 \mathrm{~nm}$. The signal intensity reaches a maximum when the appearance of the $388 \mathrm{~nm}$ band heralds the maximum formation of the MVS. Further oxidation to the fully oxidized species resulted in a decrease in the ESR signal intensity to a final value of about $50 \%$ that of the maximum intensity. Re-reduction of the solution via the MVS gave an initial increase in the ESR intensity followed by a decrease to zero upon formation of the initial species.

The MVS of $[\mathrm{ZnTrNPc}]_{4}$ is a biradical cation which evidently has small or negligible interaction between the two electrons, as for example observed with $\left.\mathrm{Ru}\left(2,2^{\prime} \text {-bipyridine }\right)_{3}\right]^{\circ}$, obtained through two-electron reduction of the $\left[\operatorname{Ru}\left(2,2^{\prime}\right.\right.$ bipyridine) $\left.]_{3}\right]^{2+}$ cation. ${ }^{51}$ On further oxidation the electrons in the other pair of ligands interact with the previously oxidized pair which causes the esr signal intensity to decrease. Thus in the fully oxidized species there is significant interaction between the four oxidized ligands, but it is not strong enough to relax the esr signal completely.

In contrast, oxidation of the binuclear porphyrin complex $[(\mathrm{OEP}) \mathrm{Nb}]_{2} \mathrm{O}_{3}$ beyond the second oxidation wave, resulted in the complete disappearance of the free radical ESR signal. ${ }^{17}$ One-electron ring-oxidation of neutral MV lanthanide diphthalocyanine sandwich complexes also results in the loss of the free radical signals. ${ }^{8,10,11}$

The $\mathrm{g}$ values for the MVS and $\mathrm{OxOx}[\mathrm{ZnTrNPc}]_{4}$ species are equal, at 2.001, and their peak-to-peak separations are similar and typical for a $\pi$-cation phthalocyanine radical species. The $\mathrm{g}$ values for the species $[\mathrm{LZnPc}(-1)]^{+}$, where $\mathrm{L}=\mathrm{Im}, \mathrm{Py}$ or $\mathrm{CN}^{-}$lie between ${ }^{26} 2.0055$ and 2.0068 , while $\mathrm{g}$ values close to 2.00 are reported for a wide range of phthalocyanine radical cations. ${ }^{4,7,8,11,40,50,52,53}$

\section{Conclusions}

The electrochemical and spectroelectrochemical data show that the oxidation of phthalocyanine ligands in $\mathrm{EtMeO}(5)[\mathrm{ZnTrNPc}]_{2}$ takes place by two stepwise oneelectron processes. In $[\mathrm{ZnTrNPc}]_{4}$, oxidation of the phthalocyanine ligands occurs in two steps in which each step involves two simultaneous and independent one- 
electron processes. Initially, all four phthalocyanine rings are stereochemically equivalent. In the first step two rings are oxidized to form the MVS. This is believed to assume a conformation in which half-oxidized pairs of rings $(\operatorname{Pc}(-2) \cdot \operatorname{Pc}(-1))$ associate, perhaps to generate a $D_{2 d}$ conformation about the central (spiro) carbon atom.

The difference in the redox potentials observed for the SS/MVS and MVS/OxOx couples merits comment. Although splitting of redox peaks was seen for the Co(II)/ Co(I) couple of 'clamshell' cobalt porphyrins, ${ }^{1}$ no such splitting has been observed for any of the corresponding binuclear Co phthalocyanines. ${ }^{20}$ The electronic coupling between the cobalt atoms is not sufficient to cause an observable splitting, and the two units of each molecule oxidize or reduce simultaneously. However, this study shows that bi- or tetranuclear ZnTrNPcs with 'clamshell' conformation in solution have significant interaction between the ZnTrNPc units which results in observable splitting of the first oxidation wave. The proposal that the MVS is partially delocalized over two phthalocyanine rings may explain why the MVS has special stability, but does not explain why the cobalt derivatives should not form a similar species. The explanation may lie in a balance between the relative free energies of axial binding by solvent or supporting electrolyte ions and the MVS electronic coupling. An interposing axial group may prevent the two phthalocyanine groups from moving close enough together to form a stable electronically coupled MVS in the cobalt series, but not in the zinc series.

The existence of these compounds provides a new avenue of research into the study of mixed-valence phthalocyanine species, hitherto undeveloped. ${ }^{2,3}$

\section{ACKNOWLEDGEMENTS}

We are indebted to the Natural Sciences and Engineering Research Council (Ottawa), and the Office of Naval Research (Washington), for financial support. We also wish to acknowledge Prof. N. Kobayashi (Tohoku University) for making available his thin layer cell, Dr. M. Neal Golovin for the coulometric data and S. Greenberg for synthetic assistance.

\section{REFERENCES}

1. J.P. Collman, M. Marrocco, C.M. Elliot and M. L'Her, J. Electroanal. Chem., 124, 113 (1981); Y. Le Mest, M. L'Her, J. Courtot-Coupez, J.P. Collman, E.R. Evitt and C.S. Bencosme, J. Electroanal. Chem., 184, 331 (1985).

2. C.C. Leznoff, H. Lam, S.M. Marcuccio, W.A. Nevin, P. Janda, N. Kobayashi and A.B.P. Lever, Chem. Comm., 699 (1987).

3. C.C. Leznoff, H. Lam, W.A. Nevin, N. Kobayashi, P. Janda and A.B.P. Lever, Angew. Chem., 99, 1065 (1987)

4. J.P. Collman, K. Kim and C.R. Leidner, Inorg. Chem., 26, 1152 (1987).

5. J.P. Collman, J.W. Prodolliet and C.R. Leidner, J. Am. Chem. Soc., 108, 2616 (1986).

6. The standard oxidation state of the dinegative phthalocyanine anion, $\mathrm{Pc}^{-2}$ is referred to as $\mathrm{Pc}(-2)$, and thus the radical "cation", $\mathrm{Pc}^{-}$, is $\mathrm{Pc}(-1)$, and the radical anion, $\mathrm{Pc}^{-3}$, as $\mathrm{Pc}(-3)$, according to the nomenclature introduced previously. ${ }^{7}$

7. J.F. Myers, G.W. Rayner and A.B.P. Lever, Inorg. Chem., 14, 461 (1975).

8. G.A. Corker, B. Grant and N.J. Clecak, J. Electrochem. Soc., 126, 1339 (1979).

9. E.I. Kapinus, L.I. Smiykalova, and I.I. Dilung, Zh. Neorg. Khim., 25, 412 (1980).

10. A.T. Chang and J-C. Marchon, Inorg. Chim. Acta, 53, L241 (1981). 
11. L.G. Tomilova, E.V. Chernyk?, V.I. Gavrilov, I.V. Shelepin, V.M. Derkacheva and E.A. Lukyanets, Zh. Obshch. Khim., 52, 2606 (1982).; L.G. Tomilova, E.V. Chernykh, N.T. Ioffe and E.A. Luk'yanets, Zh. Obshch. Khim., 53, 2594 (1983).

12. M. L'Her, Y. Cozien and J. Courtot-Coupez, J. Electroanal. Chem., 157, 183 (1983).

13. M. M'Sadak, J. Roncali and F. Garnier, J. Chim. Phys., 83, 211 (1986).

14. K. Kasuga, M. Ando and H. Morimoto, Inorg. Chim. Acta, 112, 99 (1986).; K. Kasuga, H. Morimoto and M. Ando, Inorg. Chem., 25, 2478 (1986).

15. J.W. Buchler and K. Elsasser, Angew. Chem. Int. Ed. Engl., 25, 286 (1986).

16. M.J. Crossley and P.L. Burn, Chem. Comm., 39 (1987).

17. J.E. Anderson, Y.H. Liu, R. Guilard, J-M. Barbe and K.M. Kadish, Inorg. Chem., 25, 2250 (1986).

18. D.W. De Wulf, J.K. Leland, B.L. Wheeler, A.J. Bard, D.A. Batzel, D.R. Dinning and M.E. Kenney, Inorg. Chem., 26, 266 (1987).

19. T.M. Mezza, N.R. Armstrong, G.W. Ritter, J.P. Iafalice and M.E. Kenney, J. Electroanal. Chem., 137, 227 (1982).

20. W.A. Nevin, M.R. Hempstead, W. Liu, C.C. Leznoff and A.B.P. Lever, Inorg. Chem., 26, 570 (1987).

21. W.A. Nevin, W. Liu, S. Greenberg, M.R. Hempstead, S.M. Marcuccio, M. Melnik, C.C. Leznoff and A.B.P. Lever, Inorg. Chem., 26, 891 (1987).

22. A. Giraudeau, Fu-Ren Fan and A.J. Bard, J. Am. Chem. Soc., 102, 5137 (1980).

23. V.I. Gavrilov, L.G. Tomilova, I.V. Shelepin and E.A. Luk yanets, Elektrokhimiya, 15, 1058 (1979).

24. A.B.P. Lever, S. Licoccia, K. Magnell, P.C. Minor and B.S. Ramaswamy, Advances in Chemistry, 20, 237 (1982); D.W. Clack, N.S. Hush and I.S. Woolsey, Inorg. Chim. Acta, 19, 129 (1976); R.O. Loutfy and Y.C. Cheng, J. Chem. Phys., 73, 2902 (1980).; T. Shen, Z. Yuan and H. Xu, Acta PhysChim. Sinica, 1, 265 (1985).

25. A. Giraudeau, A. Louati, M. Gross, J.J. Andre, J. Simon, C.H. Su and K.M. Kadish, J. Am. Chem. Soc., 105, 2917 (1983).

26. T. Nyokong, Z. Gasyna and M.J. Stillman, Inorg. Chem., 26, 548 (1987).

27. S.F. Vul'fson, O.L. Kaliya, O.L. Lebedev and E.A. Luk'yanets, Zhur. Organ. Khim., 12, 123 (1976).

28. T. Nyokong, Z. Gasyna and M.J. Stillman, Inorg. Chem., 26, 1087 (1987).

29. A. Loutai, M. El Moray, J. Andre, J. Simon, K.M. Kadish, M. Gross and A. Giraudeau, Inorg. Chem., 24, 1175 (1985).

30. A.J. Bard and L.R. Faulkner, "Electrochemical Methods", (John Wiley, New York, 1980).

31. R.R. Gagne, C.A. Koval and D.C. Lisensky, Inorg. Chem., 19, 2854 (1980).

32. G. Gritzner and J. Kuta, Electrochim. Acta, 29, 869 (1984).

33. N. Kobayashi and N. Nishiyama, J. Phys. Chem., 89, 1167 (1985).

34. C.C. Leznoff, S.M. Marcuccio, S. Greenberg, A.B.P. Lever and K.B. Tomer, Can. J. Chem., 63, 623 (1985).

35. E.S. Dodsworth, A.B.P. Lever, P. Seymour and C.C. Leznoff, J. Phys. Chem., 89, 5698 (1985).

36. W.A. Nevin, W. Liu and A.B.P. Lever, Can. J. Chem., 65, 855 (1987).

37. W.A. Nevin, W. Liu, M. Melnik and A.B.P. Lever, J. Electroanal. Chem., 213, 217 (1986), and references therein.

38. D. Dolphin, B.R. James, A.J. Murray and J.R. Thornback, Can. J. Chem., 58, 1125 (1980).

39. T. Nyokong, Z. Gasyna and M.J. Stillman, Inorg. Chim. Acta, 112, 11, (1986).

40. G. Ferraudi, S. Oishi and S. Muraldiharan, J. Phys. Chem., 88, 5261 (1984).

41. N.B. Subbotin, L.G. Tomilova, N.A. Kostromina and E.A. Luk'yanets, Zh. Obshch. Khim., 56, 345 (1986).

42. H. Yamamoto, T. Sugiyama and M. Tanaka, Jap. J. Appl. Phys., 24, L305 (1985).

43. M.G. Gal'pern, T.D. Talismanova, L.G. Tomilova and W.A. Luk'yanets, Zh. Obshch. Khim., 55, $1099(1985)$.

44. a) H. Homborg, Z. anorg. allg. Chem., 507, 35 (1983); b) H. Homborg and C. L. Teske, Z. anorg. allg. Chem., 527, 45 (1985).

45. N.B. Subbotin, L.G. Tomilova, N.A. Kostromina and E.A. Luk'yanets, Zh. Obshch. Khim., 56, 397 (1986).

46. We thank a referee for pointing out that even when there is no splitting of the multi-electron electrochemical wave, an MVS can exist for entropy reasons, i.e., $\mathrm{SS}+\mathrm{OxOx} \rightarrow 2 \mathrm{MVS} ; \mathrm{K}_{\mathrm{com}}=4$.

47. J.S. Coleman, L.P. Varga and S.H. Mastin, Inorg. Chem., 9, 1015 (1970).

48. The ratios [MVS]/[SS] and [OxOx]/[MVS] are obtained by equating them to the expressions $\left[\mathrm{A}_{\mathrm{f}}-\mathrm{A}\right] /$ $\left[A-A_{o}\right]$ where $A$ is the observed absorbance. The data are shown in Fig. $2 b$. The $A_{o}$ and $A_{f}$ terms correspond appropriately to the initial absorbance (data were used at $680 \mathrm{~nm}$ ) (SS) and final absorbance at $0.75 \mathrm{~V}(\mathrm{OxOx})$. For MVS, the spectrum at $0.58 \mathrm{~V}$ was assumed to represent $80 \% \mathrm{MVS}$ (via Fig. 4) and the $A_{0}$ and $A_{i}$ absorbance values derived therefrom accordingly.

49. P.C. Minor, M. Gouterman and A.B.P. Lever, Inorg. Chem., 24, 1894 (1985). 